J. Clin. Chem. Clin. Biochem.

Vol. 26, 1988, pp. $435-439$

(C) 1988 Walter de Gruyter \& Co. Berlin - New York

\title{
Development of Immunoradiometric Assays for Human Thyroglobulin Using Monoclonal Antibodies and the Biotin/Avidin System ${ }^{1}$ )
}

\author{
By H. Pfahl, B. Heilig, H. Bethäuser, M. Hüfner \\ Medizinische Klinik und Poliklinik V, Universität Heidelberg \\ H. Schmidt-Gayk \\ Chirurgische Klinik, Universität Heidelberg and
}

M. Junker

Medizinische Klinik I, Universität Heidelberg/Mannheim, Mannheim

(Received October 15, 1987/March 7, 1988)

Summary: Monoclonal antibodies against human thyroglobulin were produced by the hybridoma technique. Using three non-crossreactive monoclonal antibodies, an IRMA system was developed, with a polyclonal rabbit antibody fixed on microtiter plates as first extracting antibody. The monoclonal antibodies were used as second antibody, while anti-mouse IgG-biotin from goat and $\left.{ }^{125} \mathrm{I}\right]$ streptavidin served as the indicator system. The source of the monoclonal antibodies was diluted culture medium without purification. Sensitivities of $3-4 \mu \mathrm{g} / \mathrm{l}$ were obtained with all 3 monoclonal antibodies; interassay variation was about $5 \%$. This test system will be used for further immunological characterization of circulating thyroglobulin in different thyroid diseases.

\section{Introduction}

Thyroglobulin is the most characteristic protein of the thyroid gland. In small quantities it is regularly found in the circulation but the exact mechanism which leads to the appearance of this compound in the blood stream is still unclear. Thyroglobulin has a molecular weight of about 660000 and is composed of two polypeptide chains and a carbohydrate moiety of about $10 \%$ of the molecular weight (1). Microheterogeneity of thyroglobulin is a well-known phenomenon; it might be partly due to different extents of iodination of the subunits and variations of the carbohydrate moiety.

For the clinician, thyroglobulin is a very important tumour marker in the follow-up of patients treated for differentiated thyroid cancer. There is some evi-

1) This work was supported by a grant of the Tumorzentrum Heidelberg/Mannheim. dence that tumour thyroglobulin is different from thyroglobulin of the normal thyroid gland $(2-6)$. To improve the thyroglobulin test system it is therefore important to clarify whether there is a particular heterogeneity of tumour thyroglobulin and whether this is of diagnostic importance.

We have developed an immunoradiometric system for the measurement of serum thyroglobulin which can use different non-crossreactive monoclonal antibodies against thyroglobulin.

\section{Materials and Methods}

Materials

Titertek microtitre plates (Titertek 77-17305) from Flow Lab.: rabbit anti-human thyroglobulin immunoglobulins from Dakopatts; thyroglobulin standard and [ $\left.{ }^{125} \mathrm{I}\right]$ labeled thyroglobulin from Henning Berlin $\mathrm{GmbH}$; goat anti-mouse immunoglobulinbiotin and [125I]streptavidin from Amersham: gelatin from Serva, Heidelberg. All other reagents were of the usual analytical grade. 


\section{Production of monoclonal antibodies}

Monoclonal antibodies were produced by the hybridoma technique as described previously (7). In short: $\mathrm{Balb} / \mathrm{C}$ mice were injected several times with $0.5-1.0 \mathrm{mg}$ human thyroglobulin which had been extracted from euthyroid goiters by ammonium sulphate precipitation. Spleen cells were fused with $X 63 \mathrm{Ag}$ 8.653 myeloma cells 3 days after the last booster injection. Supernatants of growing clones were screened for thyroglobulin antibody by RIA ( $50 \mu$ l supernatant, $50 \mu \mathrm{l}\left[{ }^{125} \mathrm{I}\right]$ thyroglobulin (Henning/Berlin), $400 \mu \mathrm{l}$ tris $\mathrm{HCl} \mathrm{pH} 7.4+10 \mathrm{~g} / \mathrm{l}$ bovine serum albumin).

\section{Antibody purification}

Monoclonal antibodies were purified from supernatants of isolated clones $(50-100 \mathrm{ml})$ by Affi-Gel Protein A MAPS, BioRad.

Purified antibody was iodinated with ${ }^{125} \mathrm{I}$ by the chloramine $\mathrm{T}$ method as described previously (7). The iodinated monoclonals were used in cross inhibition experiments.

\section{General design of the immunoradiometric assay}

Microtitre plates were coated with $50 \mu$ rabbit anti-human thyroglobulin IgG in carbonate buffer, $\mathrm{pH} 10.6,0.2 \mathrm{~mol} / 1$ for $20 \mathrm{~h}$ at $4{ }^{\circ} \mathrm{C}$. This was followed by a blocking step to absorb unoccupied binding sites $(10 \mathrm{~g} / 1$ gelatin for $1 \mathrm{~h})$. After washing 3 times with phosphate buffered saline, thyroglobulin standards or unknown samples $(50 \mu \mathrm{l})$ were incubated for $2 \mathrm{~h}$ at room temperature. After another washing step (3 times phosphate buffered saline) monoclonal antibody was incubated for $1 \mathrm{~h}$. This was followed by a further wash ( 3 times phosphate buffered saline) and incubation with goat anti-mouse IgG-biotin. There was no crossreaction of the anti-mouse IgG-biotin with the coated rabbit IgG. Finally, after intensive washing ( 4 times phosphate buffered saline), [25 $\left.{ }^{12}\right]$ labeled streptavidin was applied for $1 \mathrm{~h}$. After a final washing step ( 3 times phosphate buffered saline), the wells were counted in a gamma counter. All phosphate buffered saline solutions for washing contained $5 \mathrm{ml} / 1$ Tween 20.

\section{Results}

Using cross blocking experiments, we selected 3 monoclonal antibodies, specific for 3 different antigenic epitopes. An example of such experiments is shown in figure 1 for labeled antibodies $\mathrm{Tg} 11$ and $\operatorname{Tg} 13$. Both antibodies were purified by protein $\mathrm{A}$ sepharose and labeled by the chloramine $\mathrm{T}$ method. As demonstrated, binding of labeled $\mathrm{Tg} 11$ was inhibited by antibodies 48, 46, 62, 67, whereas antibody 13 showed no crossreaction with these antibodies. For further studies the non-crossreacting antibodies $\mathrm{Tg}$ $11, \mathrm{Tg} 13$ and $\mathrm{Tg} 40$ were chosen; the affinity constants of the three antibodies, calculated by the method of Müller (8), were $1.02 \times 10^{10} \mathrm{l} / \mathrm{mol}(\mathrm{Tg} 11), 3.2 \times 10^{10}$ $\mathrm{l} / \mathrm{mol}(\mathrm{Tg} 13)$ and $1.15 \times 10^{9} \mathrm{l} / \mathrm{mol}(\mathrm{Tg} 40)$; all antibodies were of the IgG2 class.

Figure 2 shows the results obtained by varying the coating (first) antibody. Three thyroglobulin concentrations in buffer were used and the procedure was performed as described in the section on materials

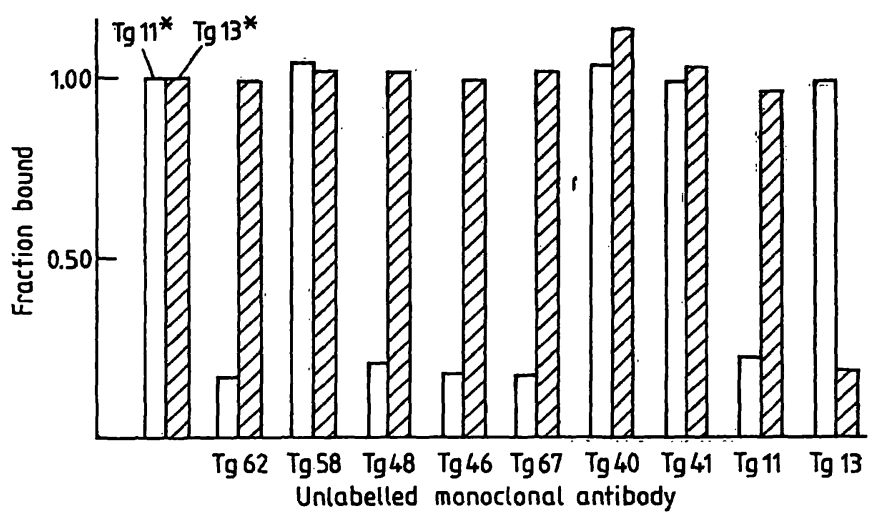

Fig. 1. Cross-blocking experiments with the $\left[{ }^{125} \Pi\right]$ labeled monoclonal antibodies $\mathrm{Tg} 11$ and $\mathrm{Tg} 13$. The abscissa indicates the respective unlabeled monoclonal antibody which was preincubated. Microtitre plates were coated with human thyroglobulin $(10 \mathrm{mg} / \mathrm{l})$. Binding of labeled $\mathrm{Tg}$ 11 and $\mathrm{Tg} 13$ without preincubation with cold antibody was set at 1.00 .

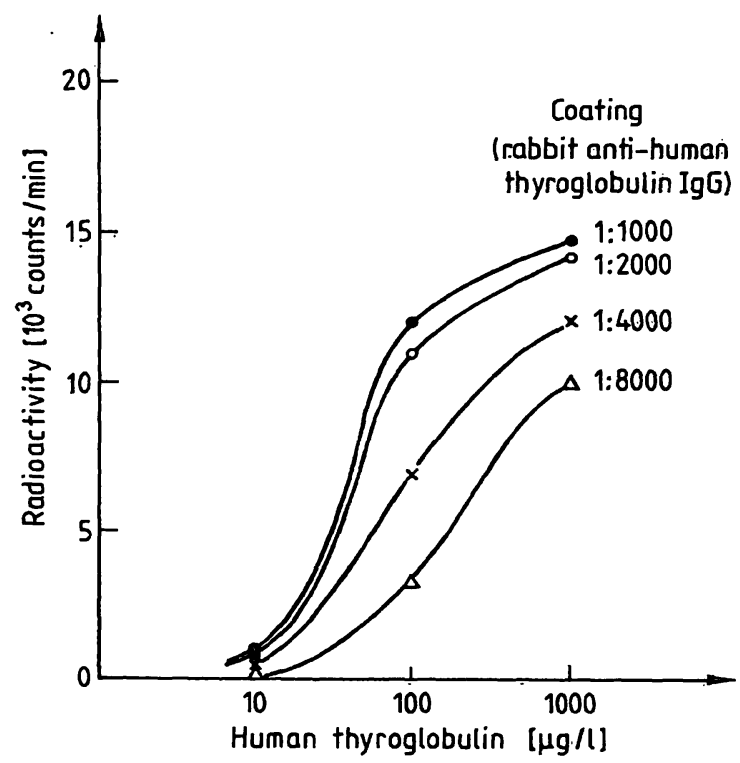

Fig. 2. Different concentrations of rabbit anti-human thyroglobulin IgG were coated (๑- 1:1000; $0-1: 2000$; $x-1: 4000 ; \Delta-1: 8000$ ) followed by incubation with 3 concentrations of human thyroglobulin $(10,100,1000$ $\mu \mathrm{g} / \mathrm{l})$; second antibody: $\mathrm{Tg} 13(1: 10)$; finally, goat antimouse IgG-biotin as described under "Method's".

and methods. The second antibody in this case was $\mathrm{Tg} 13$, and after incubation with anti-mouse IgGbiotin, radioactive streptavidin was counted. The optimal titre of the coating antibody was about $1: 2000$; this titre was used in further experiments.

Figure 3 shows the test results obtained with variations of the monoclonal antibody, in this case $\mathrm{Tg} 13$. It is obvious that the supernatant of the clone $\operatorname{Tg} 13$ contains antibody in excess, and we decided to use a $1: 10$ dilution of this particular supernatant. It seems important to determine the optimal concentrations for each monoclonal antibody, to avoid results that contain unnecessarily high levels of unspecific binding. 


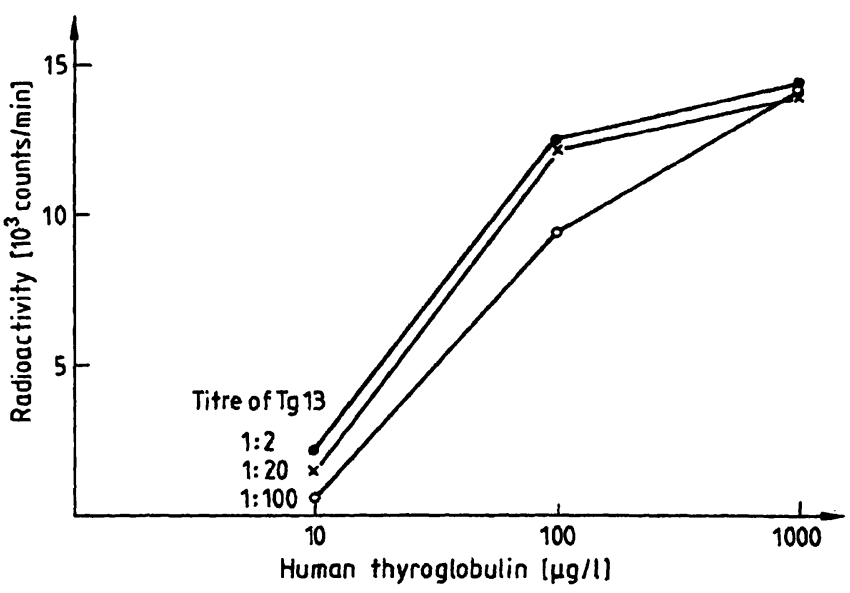

Fig. 3. Coating with rabbit anti-human thyroglobulin IgG $1: 2000$. Different titres of the second antibody $(\mathrm{Tg} 13)$. - $1: 2 ; x-1: 20 ; 0-1: 100$. Other conditions as in figure 2 .

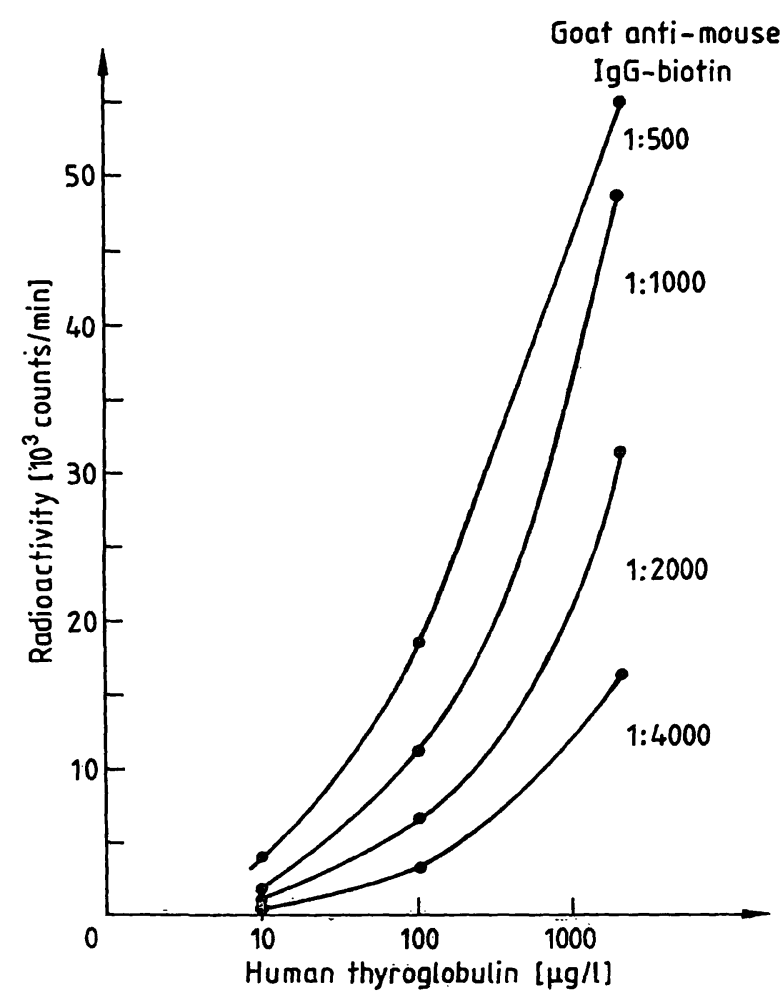

Fig. 4. Different titres of goat anti-mouse IgG-biotin; further conditions as in figure 2.

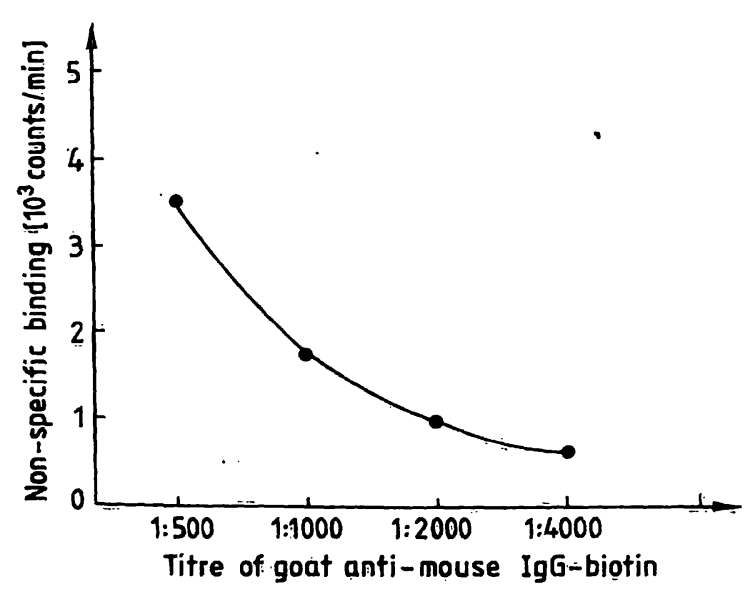

Fig. 5. Dependence of unspecific binding on variations of goat anti-mouse IgG-biotin; conditions as in figure 2.
Finally we investigated the effect of different amounts of biotin-labeled anti-mouse IgG in this system. Figure 4 demonstrates that increasing amounts of antimouse IgG-biotin led to increased binding of $\left[{ }^{125} \mathrm{I}\right]$ avidin. However, as shown in figure 5 , increasing the titre from $1: 1000$ to $1: 500$ results in an disproportionate increase of nonspecific binding. This means that most of the increasing counts observed with high concentrations of anti-mouse IgG-biotin are due to nonspecific binding. Most of this nonspecific binding seems to be due to some residual cross-reactivity of the anti-mouse IgG with the coated rabbit anti human thyroglobulin IgG. The optimal concentration of antimouse IgG-biotin is in the titre range of $1: 1000$ to $1: 2000$. Figure 4 and 5 demonstrate that a compromise has to be accepted between optimal specific binding and minimal nonspecific binding. We chose a titre of $1: 1000$ because the nonspecific binding of 2000 counts/min seemed reasonable in comparison to the steepness of the curve. However, it might turn out that conditions with lower nonspecific binding might be preferential, especially in the lower thyroglobulin concentration range. It becomes evident from this experiment that anti-mouse IgG-biotin is one of the limiting factors in this system, and that it is impossible to use this reagent in excess.

Table 1 summarized the exact conditions of the IRMA worked out by the demonstrated experiments, and figure 6 shows standard curves of 3 different assays with 3 different monoclonal antibodies in serum standards. The levelling off in the high concentration range, which is usually not seen in conventional IRMA systems, is due to the above-mentioned limitation on the amount of anti-mouse IgG-biotin which

Tab. 1. Flow diagram for a human thyroglobulin IRMA with monoclonal antibodies using the biotin-avidin system

1. Coat Titertek microtitre plates with rabbit anti-human thyroglobulin (pH 10.6, $50 \mu \mathrm{l} ; 1: 2000$, from Dakopatts)

2. Block with $10 \mathrm{~g} / \mathrm{l}$ gelatin, $1 \mathrm{~h}$

3. Wash $3 \times$ with phosphate buffered saline

4. Incubate $50 \mu$ l standard or sample diluted $1: 2$ with phosphate buffered saline, $2 \mathrm{~h}$

5. Wash $3 \times$ with phosphate buffered saline

6. Add monoclonal antibody, $50 \mu \mathrm{l}$, in appropriate dilution, $1 \mathrm{~h}$

7. Wash $3 \times$ with phosphate buffered saline

8. Add goat anti-mouse IgG-biotin (Amersham), 1:1000$1: 2000$ in phosphate buffered saline, $50 \mu \mathrm{l}, 1 \mathrm{~h}$

9. Wash $4 \times$ with phosphate buffered saline

10. Add streptavidin ${ }^{125} \mathrm{I}(100000$ counts $/ \mathrm{min}) 50 \mu \mathrm{l}, 1 \mathrm{~h}$

11. Wash $3 \times$ with phosphate buffered saline, count. 


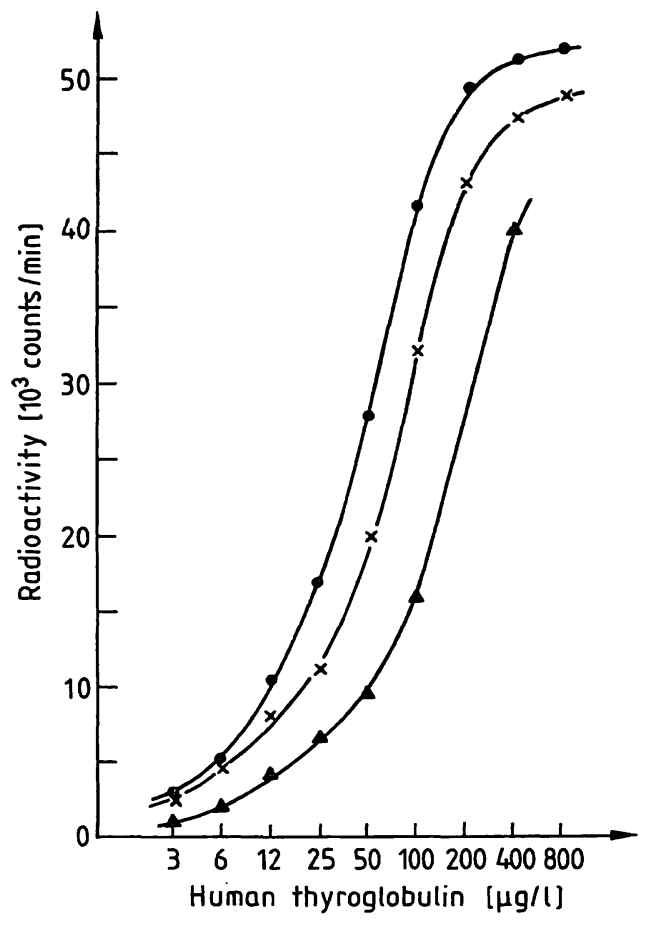

Fig. 6. Standard curves of 3 different non-cross-reacting mouse monoclonal antibodies; $-\mathrm{Tg} 13 ; \mathrm{x}-\mathrm{Tg} 40 ; \Delta-\mathrm{Tg}$ 11 (II. antibody). I. antibody: rabbit polyclonal antihuman thyroglobulin IgG. For exact conditions see table 1 .

can be used in this system. In table 2 some statistical data of these three assay systems are summarized. The sensitivity (three standard deviations at zero point) and the intra- and inter-assay variations (at 50 $\mu \mathrm{g} / \mathrm{l})$ are similar in all 3 systems and seem comparable with those of most polyclonal assays.

Tab. 2. Analytical performance of the assays

\begin{tabular}{llll}
\hline & $\begin{array}{l}\text { IRMA } \\
\operatorname{Tg} 13\end{array}$ & $\begin{array}{l}\text { IRMA } \\
\text { Tg 11 }\end{array}$ & $\begin{array}{l}\text { IRMA } \\
\text { Tg 40 }\end{array}$ \\
\hline Sensitivity $(\mu \mathrm{g} / \mathrm{l})$ & 4.0 & 3.0 & 3.0 \\
$\begin{array}{l}\text { Intra-assay variation } \\
(20 \mu \mathrm{g}(\mathrm{l}) \mathrm{n}=10\end{array}$ & $1.1 \%$ & $2.6 \%$ & $1.8 \%$ \\
$\begin{array}{l}\text { Inter-assay variation } \\
(20 \mu \mathrm{g} / \mathrm{l}) \mathrm{n}=8\end{array}$ & $5.4 \%$ & $1.5 \%$ & $4.8 \%$ \\
$\begin{array}{l}\text { Recovery }\left(50 \mu \mathrm{g} / \mathrm{l}^{*}\right) \\
\mathrm{n}=8 ; \mathrm{x} \pm \mathrm{SD}\end{array}$ & $52.8 \pm 2.8$ & $49.7 \pm 0.76$ & $55.2 \pm 4.0$ \\
\hline
\end{tabular}

- Henning standard

\section{References}

1. Van Herle, A. G. (1987) Thyroglobulin synthesis and metabolism: clinical aspects; In: Thyroglobulin and thyroglobulin antibodies in the follow-up of thyroid cancer and endemic goiter (Hüfner, M. \& Reiners, Ch., eds.) Georg Thieme Verlag Stuttgart, New York, pp. $21-30$.

2. Izumi, M., Cahnmann, H. J. \& Robbins, J. (1977) Endocrinology $100,1448-1460$.
Using this system in 12 normal individuals plasma thyroglobulin concentrations were measured simultaneously. The mean value obtained was $17.2 \mu \mathrm{g} / \mathrm{l}$ for $\operatorname{Tg} 11,20.3 \mu \mathrm{g} / 1$ for $\mathrm{Tg} 13$ and $20.6 \mu \mathrm{g} / \mathrm{l}$ for $\mathrm{Tg} 40$. The difference was statistically not significant.

\section{Discussion}

Monoclonal antibodies are widely used today in diagnostic tests for different hormones and various drugs. Several tests, for instance the thyrotropin assay, have been considerably improved, especially by use of the IRMA technique.

Thyroglobulin is a very complex macromolecule and it is still unproven whether the use of monoclonal antibodies will be of advantage in the radioimmunological determination of serum thyroglobulin. In particular, the possibility of tumour-specific variants of antigenic epitopes of thyroglobulin might be a problem $(3,4,6,8)$. On the other hand, it might be possible to develop a thyroglobulin test system which is not influenced by autoantibodies, because the epitope specificity of autoantibodies seems to be very limited (9).

We describe an IRMA system for thyroglobulin measurement in serum which uses a polyclonal rabbit antibody as first extracting antibody and mouse monoclonal antibody as second. The second antibody consists of diluted culture medium of specific unlabelled clones. A biotin-labeled anti-mouse IgG (goat) and $\left[{ }^{125} \mathrm{I}\right]$ labeled avidin serve as indicators. Thus the monoclonal antibodies can easily be exchanged for different epitope specificity. By the systematic use of different non cross-reacting monoclonal antibodies we are now able to investigate the preservation or deletion of various antigenic epitopes of serum thyroglobulin in thyroid cancer patients. By this sensitive device we will be able to clarify whether the postulated increased immunological heterogeneity of tumour thyroglobulin really exists and, if so, whether it is of diagnostic significance. In general, it will be possible to investigate whether thyroglobulin species specific for thyroid disease can be found in the circulation.

3. Mariotti, S., Bechi, R., Anelli, S., Pacini, F., Wall, J. R. \& Pinchera, A. (1984) Use of monoclonal antibodies to assess the antigenic heterogeneity of human thyroglobulin; International Symposium on Monoclonal Antibodies 84, Florence, Abstract 84.

4. Heilig, B., Hüfner, M.. Dörken, B. \& Schmidt-Gayk, H. (1986) Klin. Wochenschr. 64, 776-780. 


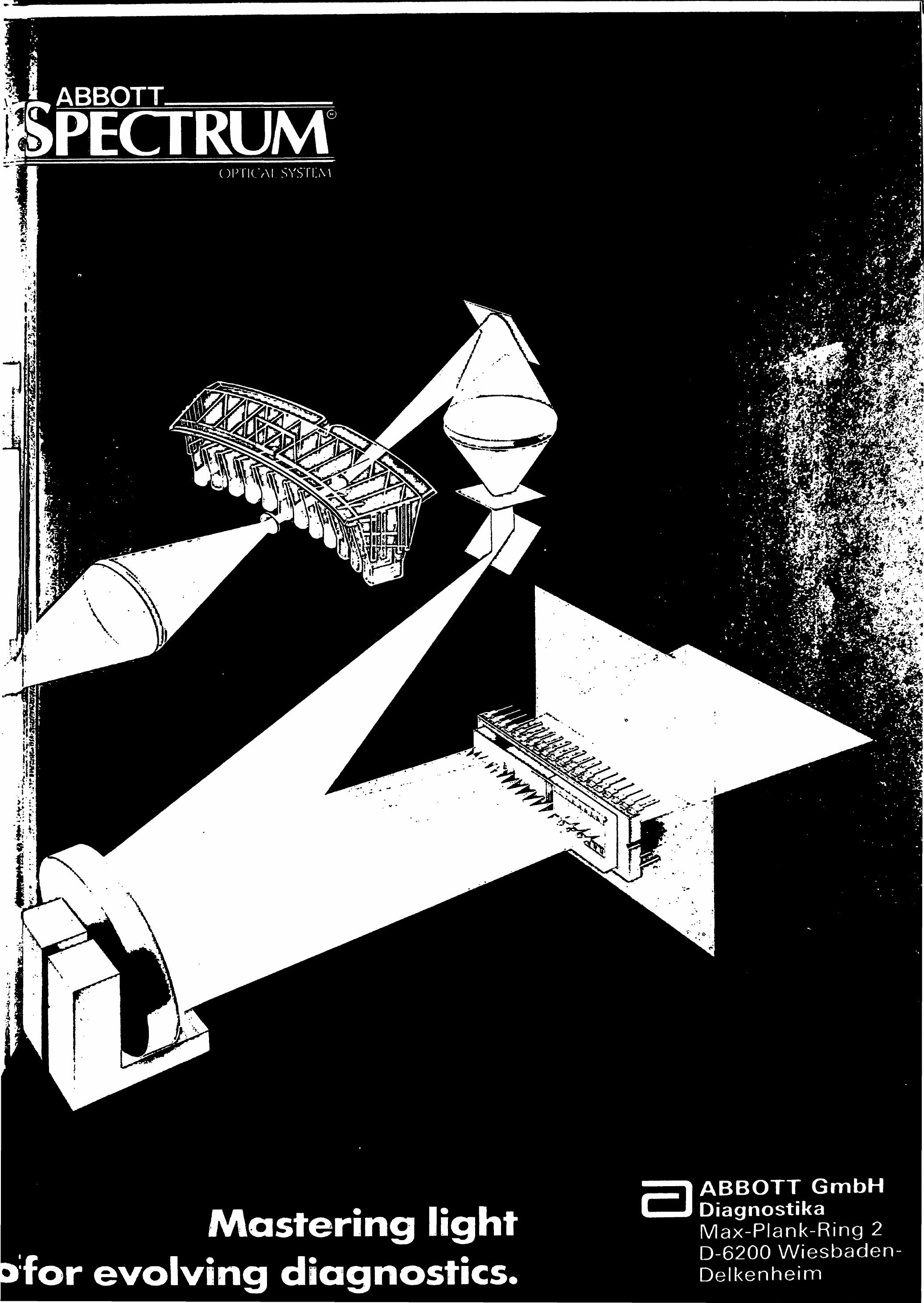




\section{Lymaphecyte Activation and Differentiation}

\section{Fundamental and Clinical Aspects}

\section{Proceedings of the 18th International Leucocyte Culture Conference La Grande Motte, France, June 19-24, 1987}

\section{Editors J. C. Mani $\cdot J$. Dornand}

$1988.17 \mathrm{~cm} \times 24 \mathrm{~cm}$. XXII, 960 pages. With numerous illustrations. Hardcover DM 360,- ISBN 3110107600

This volume presents the latest data in the essentially growing field of leucocyte culture. It mainly concerns both fundamental and clinical specialists of the following fields: Immunology, cellular biology, molecular biology, immunopharmacology, cancerology, transplantations, immunotherapy, growth factors, second messengers, oncogens, membrane receptors and transmembrane signalling.

Contents (Main Chapters):

Introduction $\cdot$ Plenary Lecture.

Symposia: Biochemical and Cellular Aspects of Lymphocyte Activation - Differentiation of T and B Lymphocytes - Molecular Biology of Leucocytes (Antigens, Receptors, Interleukins) · Virus-Induced Lymphocyte Dysfunctions · Accessory Cell Functions.

Workshops: Growth and Differentiation Factors - Mechanisms of Autoimmunity Oncogenes and Leucocyte Transformation - Experimental Models of Immunomodulation - Immunodeficiencies · Natural Killer Cells · Differentiation and Activation of T Lymphocytes - Differentiation and Activation of B Lymphocytes . Lipidic Mediators of the Immune Response - Neural Modulation of Immunity • Biochemistry of Leucocyte Stimulation and Effector Mechanisms - Accessory Cells-Lymphocyte Interactions - Idiotypic Regulation - Complement Receptors · Major Histocompatibility Complex · Clinical Applications of Anti-Leucocyte Monoclonal Antibodies. 
5. Kohno, Y., Tarutani, O., Sakata, S. \& Nakajimy, H. (1985) J. Clin. Endocrinol. Metab. 61, 343-350.

6. Schneider, A. B., Ikekubo, K. \& Kuma, K. 81983) J. Clin. Endocrinol. Metab. 57, 1251-1256.

7. Heilig, B., Hüfner, M., Dörken, B. \& Schmidt-Gayk, H. (1986) Ärztl. Lab. 32, 85-90.

8. Müller, R. (1983) Enzymology 92, 589-601.
9. Ruf, J., Henry, M., De Micco, C. \& Carayon, P. (1987) Characterization of monoclonal and autoimmune antibodies to thyroglobulin; applications to clinical investigation. In: Thyroglobulin and thyroglobulin antibodies in the followup of thyroid cancer and endemic goiter (Hüfner, M. \& Reiners, Ch., eds.) Georg Thieme Verlag Stuttgart, New York, pp. 21-30.

Prof. Dr. Michael Hüfner

Med. Poliklinik

Im Neuenheimer Feld

D-6900 Heidelberg 
